\title{
EVALUATION AND QUALIFICATION OF ENVIRONMENTALLY CONSCIOUS MANUFACTURING PROCESSES FOR COMMERCIAL AND MILITARY APPLICATIONS
}

\author{
Dennis J. Anderson \\ Robert M. Cranwell \\ Ronald L. Iman \\ Phillip D. Van Buren \\ Sandia National Laboratories \\ P.O. Box 5800 \\ Albuquerque, New Mexico 87185-0746 USA
}

\begin{abstract}
Environmental regulations are encouraging the development of new environmentally conscious manufacturing (ECM) processes. However, the quality and reliability of these processes and hardware produced must be understood prior to implementing these new technologies in factories. Furthermore, military hardware fabrication is governed by standards and specifications that frequently mandate the use of older, less environmentally friendly processes or materials, or prohibit the use of new ECM processes without advance military approval. Sandia National Laboratories, with industrial and military partners, have developed methodologies for evaluating and qualifying new ECM processes for military and commercial applications, and have piloted these methodologies in qualifying new, low-residue soldering technologies and materials.
\end{abstract}

\section{INTRODUCTION}

Traditional soldering processes for electronic products use rosin flux to remove oxides and other contaminants from the surfaces to be joined and enhance solderability. If not removed after soldering, the flux can attract moisture and lead to corrosion and possible failures. Rosin flux residue is typically removed with chemical solvents that contain ozonedepleting chemicals (ODCs), mainly chlorofluorocarbons (CFCs). Considered to be major contributors to stratospheric ozone depletion, these solvents have been scheduled for phaseout and elimination. Mandates for the elimination of ODCs and impending labeling requirements in compliance with the Clean Air Act of 1990 are forcing many companies and organizations to adopt alternative processes that do not use ODCs.

Low-residue (no-clean) soldering processes use alternative flux materials that are almost entirely consumed during soldering, leaving minimal, benign residues that do not require subsequent solvent cleaning. A Cooperative Research and Development Agreement (CRADA) effort between Sandia
National Laboratories and Motorola Inc. evaluated the reliability of low-residue technology with wave soldering for printed wiring boards (PWBs). The low-residue soldering process was determined to produce reliable hardware comparable to the traditional rosin flux/solvent cleaning processed hardware. Elimination of solvent cleaning not only minimizes waste emissions but also significantly reduces: energy use; process turnaround time; and the costs associated with cleaning equipment purchase, operation, and maintenance. However, military specifications still mandate the use of chemical solvents to clean residues remaining after solder assembly. Success of the project with Motorola resulted in the formation of a 19-member Low-Residue Soldering Task Force, established and coordinated by Sandia, to evaluate and qualify the technology for military and commercial use and to transfer the technology to industry. An extensive test plan was developed to thoroughly evaluate the reliability of lowresidue wave soldering, $\mathbb{R}$ reflow soldering for surface mount components, hand soldering, and soldering of hybrid microcircuits. Test PWBs were designed to include a wide range of circuitry, components, materials, and applications. Input from each of the military branches was utilized to design the boards and establish test requirements that will be sufficient to obtain acceptance of low-residue soldering technology.

This paper describes the methodologies developed to evaluate and qualify these new processes, and presents two case studies.

\section{METHODOLOGIES}

The need to incorporate environmentally conscious processes into today's factories is mainly driven by environmental regulations. Companies must not only consider the impacts of the cost of these new processes on their marketplace competi-

This work was supnorted by the United

States Department of Energy under

Contract DE-ACn4-94AL.85000. 


\section{DISCLAIMER}

Portions of this document may be illegible in electronic image products. Images are produced from the best available original document. 
tiveness, but must also consider the impact on product quality and reliability. Additionally, companies that produce military hardware must get advance contractual approvals to use these new processes that are frequently prohibited by military specifications or standards. This has led to the development of a seven-step methodology to evaluate and qualify new processes.

\section{Step 1-Form Cooperative Team}

Soldering has been an emotional topic area in the military products arena, where the determination of the quality of a solder joint by its visual appearance is very subjective. The numerous attempts by DoD contractors to show that visual anomalies in a joint have no impact on subsequent reliability have resulted in little success in changing the minds of the military soldering community. This has led to industry searching out independent participants for their evaluations of new processes. A national laboratory, such as Sandia National Laboratories, has no vested interest in the outcomes of the technical study and thus lends credibility to the program.

Including other members from industry has numerous advantages, including: a) spreading out the total program costs; b) a wider base of experience and capabilities to apply to the program; c) additional leverage in obtaining military approvals; and d) improved credibility.

The participation of technical experts from the Army, Navy and Air Force can enhance programs that ultimately require government approval before using the new process to fabricate military hardware. Their involvement can also reduce program costs if they contribute by providing testing and other analytical tasks. Participation by commercial customers may yield similar benefits.

\section{Step 2- Determine Baseline}

The purpose of most studies is to demonstrate that the proposed process is as good as or better than the existing process. Understanding who the decision makers are and what influences their decisions -are important in developing an evaluation and qualification plan for the program. A few of the items to consider include:

1) What specifications or standards (military, commercial or internal) are involved and which parts require changing or permission to deviate? What are the specification limits that must be met? What are the test methods?

2) What are the current production metrics (yields, cycle time, etc.)?
3) What is the reliability of products produced with the existing process, and how is it verified?

\section{Step 3-Develop Evaluation and Qualification Approach}

The project team, including customers, should evaluate the baseline evaluation criteria, discussed in Step 2, to determine if it is adequate for evaluating and qualifying the new process. Potential failure modes of products in the field should also be considered. Test equipment, test methods, test vehicles, data analysis techniques and testing pass/fail criteria should be established. All of these items should be integrated into a test plan, which should be reviewed and approved (if possible) by the ultimate decision makers. The plan, or a separate manufacturing plan, should also address any material handling or storage factors that could influence the test results.

\section{Step 4-Fabricate Test Hardware}

Test hardware may consist of several designs, including those specified by applicable testing specifications, existing product designs typically fabricated with the existing process, or custom hardware that is designed to gather required data. If regular functional products are not used, consideration should be given to including functional features in custom designs. Frequently, specifications have test limits that may not be directly related to product performance, such as ionic cleanliness of printed wiring boards. Test results within such test limits, or marginally outside of them, may not be indicative of real-world product performance. A functional product, or custom hardware with functional features, will provide a better indication of hardware reliability.

If custom hardware or custom testing is involved, it may be beneficial to fabricate a limited amount of additional hardware to be used for referee tests, or for "Murphy factor" allowances.

\section{Step 5- Testing}

Testing should be performed in accordance with the test plan, taking care to document all anomalies that take place. Test equipment should be examined in advance to verify proper calibration, and re-examined after testing to assure confidence in the test results. Consideration should be given to training the personnel that collect the data, since many tests are destructive in nature.

\section{Step 6- Test Data Collection and Analysis}

Data should be collected in accordance with the techniques defined in the test plan. The data, along with testing anomalies and failure analysis data should be examined by the project team to verify that no additional testing is required. Early 
review of the data with the customer enhances their acceptance of the final program results.

\section{Step 7-Transfer Technologies}

Transferring the program results to industry, and the government if applicable, via reports and workshops helps gain a wider acceptance for the new process. This wider acceptance may enhance getting military approvals to use the new process for their hardware.

\section{CASE StudiEs}

\section{Case Study 1-Motorola CRADA}

The need to eliminate $\mathrm{CFC}$ cleaning solvents from its printed wiring board (PWB) assembly operations led Motorola to explore the use of new no-clean soldering processes. One of these new processes used a dilute adipic acid and isopropyl alcohol solution in lieu of rosin flux, and had a nitrogen and formic acid cover blanket to eliminate oxidation in the solder zone. The heat of the soldering process rendered these chemicals harmless, thus eliminating the need for subsequent cleaning. Deleting the cleaning operation eliminated the need for the CFC-based cleaning solvents, and also saved approximately $\$ 42,000$ per year in electricity for a single cleaning machine. Additional benefits included reduction of solder dross, a hazardous material, and reduced preventive maintenance for the soldering equipment. However, military standards and specifications prevented Motorola from using the new process in the production of its military products.

Motorola and Sandia National Laboratories entered into a Cooperative Research And Development Agreement (CRADA), and were assisted in the program by Los Alamos National Laboratory, the Navy's EMPF facility and the Soldering Technology Branch at the Naval Air Warfare Center at China Lake. Representatives from the Army, Navy and Air Force's soldering quality groups were also invited to review activities throughout the program.

The program had three goals: 1) to evaluate the reliability of hardware produced with the new process; 2) to verify that the new process could produce hardware that met the military specification limits for surface insulation resistance (SIR) and ionic cleanliness; and 3) to obtain military approvals to use the new process.

Three different PWB designs were used on the program: 1) a Motorola test board developed to evaluate solder joint visual quality; 2) the IPC B-24 PWB, which is used for SIR testing; and 3) the PWB from the FMU-139 bomb fuze, which was a fully functional board currently in high volume production.
The wave soldering equipment used in this study had numerous controls for parameters that affect solder joint visual quality, including three independent variable speed conveyors for the fluxing, preheat and soldering zones. Additional controls included solder temperature, single or dual waves, solder wave height, wave angle, preheat temperature, adipic acid concentration, and flow rate of the nitrogen. Recognizing that PWBs of different designs may require different combinations of soldering parameters to optimize solder joint visual quality, an experiment was designed to qualify a broad "process window" for the equipment. Soldering parameters for all PWB designs soldered in the factory with the existing process were examined, and an overall process window was defined. Maximum and minimum parameters were established for all machine controlled parameters, and a statistically designed experiment was developed. All of the PWBs were soldered at Motorola on their equipment. Additionally, "baseline" PWBs were soldered with the existing rosin flux soldering process followed by solvent cleaning.

Numerous tests typically conducted during production or product qualification were conducted [1], along with functional testing of the bomb fuze PWB and solder joint data from the Motorola test PWB. Testing included solder joint visual quality examination, solder joint mechanical and electrical data collection, ionic cleanliness, SIR testing of the B24 PWB, and surface chemical analysis. Some of the PWBs were subjected to environmental stress conditioning (after soldering and before testing), which included temperaturecycling, temperature-humidity or long-term accelerated storage testing.

Conclusions from this study included: 1) the new process produced solder joint visual quality equivalent to the existing process; 2) the process produced reliable hardware over the wide range of parameters that defined the "process window"; 3) PWBs that had ionic cleanliness measurements above the current specification limits were still reliable; 4) the minimal residues on some PWBs had no impact on hardware reliability; and 5) the new process did not degrade product life.

Results from the program were transferred to industry at a workshop in Albuquerque on January 13 and 14, 1993, and through the program final report [1]. Approximately 175 people from industry and the Government attended the workshop. Sandia received requests from over 350 companies for information on the program and over 1600 copies of the final report have been distributed.

The program had several positive results, including the development of a national laboratory, DoD and industry team that continues to work together. It also demonstrated the value of independent assessments and led to Motorola getting 
approval to use the process on several military projects. In addition, it has sparked considerable interest from industry, which resulted in a follow-on program (see Case Study 2).

Areas for future improvement included having additional industry participants. The initial program was designed to qualify the process for Motorola hardware applications; additional industry participants would have resulted in the new process being qualified for more universal applications. More formalized participation from the government soldering community might have enhanced their probability of acceptance of the process for other applications; a custom test vehicle with more performance-related features would have qualified the process for more applications; and using additional soldering technologies, such as hand soldering, could have contributed to qualifying a more "complete" solution.

\section{Case Study 2-Low-Residue Soldering Task Force (LRSTF)}

Considerable industry interest from the Motorola CRADA program led Sandia and Texas Instruments (TI) to search out additional industry and Government partners to participate in a task force to study additional low-residue soldering processes and materials. Ten (10) different companies entered into CRADAs with Sandia, including TI, Alliant Techsystems, GM Hughes Electronics, Northern Telecom, Teledyne Electronic Technologies, North Bay Blectronics, Andersen Laboratory, Phoenix Microwave Corporation, M. S. Kennedy Corporation and CTS Corporation. Eight (8) different Government related organizations are participating with Sandia on the program, including the Naval Air Warfare Center (NAWC) at China Lake, NAWC-Indianapolis, US Army-MICOM, US Air Force-Hanscom AFB, EMPF, EPA, AlliedSignal/Kansas City Division (a DOE production plant) and the National Defense Center for Environmental Excellence.

The goals of the LRSTF program are to evaluate several soldering technologies, including wave, hand and reflow soldering; to verify these technologies for several product applications; to gather data to support Government approvals of these new processes; and to transfer these technologies to industry. The LRSTF was established with a diverse membership that could facilitate incorporation of customer concerns and requirements. In addition, input to the test program was solicited from the tri-services, other government agencies, and industry through mailings and open meetings. Initially, a lengthy "shopping list" of possible requirements was developed, covering the following categories: circuit characteristics, materials, circuit technology, soldering processes, flux application techniques, testing and analysis. From this list, the LRSTF established key components to form the basis of the program test plan. Because satisfying all possible requests would be nearly impossible, the task force aimed to meet approximately $80 \%$ of the possible requirements on the list. Several subsequent meetings and additional open review led to development and finalization of the LRSTF program test plan [2].

The requirements of the test plan were best met by a custom designed, fully functional PWB, to be soldered with three different technologies: wave, reflow and hand soldering. This program also used the IPC B-24 PWB and "Y" coupons for test vehicles. The LRSTF PWB has four different functional regions to simulate different product applications. These regions included high speed digital circuitry, high-voltage/low-current circuitry, low-voltage/high-current circuitry, and high frequency circuitry. The LRSTF PWB was fabricated using both FR-4 and polyimide laminate materials.

The boards were assembled and soldered at four different manufacturing sites: TI, Alliant Techsystems, GM Hughes and AlliedSignal/KCD. The testing approach was similar to the Motorola program, except the mechanical pull strength and temperature cycling tests were deleted and a conformal coating adhesion test was added. Testing was performed at five sites: Sandia, EMPF, NAWC-China Lake, CSL Inc., and AlliedSignal/KCD.

All manufacturing and testing for Phase 1 of this program is complete. Although a few anomalies were noticed, they appear non-process related. Initial program results were presented at a workshop in Albuquerque, on November 8 and 9, 1993, with nearly 200 people from industry and the Government in attendance. The Phase 1 final report is scheduled for release in May 1995.

Positive results from this program mirror those of the Motorola program, with the following improvements: 1) the task force approach, with additional industry participants, has been well received; 2) the more formal participation from Government entities appears to have contributed to better acceptance of the technologies; 3) the participation of an independent assessor (Sandia) contributed to the acceptance of the program and its results; 4) the use of a custom, multifunction PWB enhanced the applicability of the program results; and 5) the use of multiple soldering technologies provides a more complete solution.

Additional observations from this program include: 1) it is difficult to satisfy everyone's needs despite using a custom test PWB; 2) it is very difficult to get military soldering standards and specifications changed despite having data that indicates process acceptability, coupled with overwhelming industry support and that of many government soldering technologists; and 3) more processing sites increases the need for more "Murphy factor" allowances in program planning. 


\section{CONCLUSIONS}

The methodologies developed, piloted and improved through the two case study programs provide an approach to evaluating and qualifying new, environmentally conscious manufacturing processes. This approach has been widely supported by industry and appropriate Government technical personnel. Their continuing support is evidenced by the interest in a follow-on program which evaluates lead-free solders in combination with low-residue soldering technologies.

\section{ACKNOWLEDGMENTS}

The authors wish to acknowledge the contributions of their industry and Government partners referenced in this paper. Additionally, partial funding for the Motorola program was provided by the DOE Industrial Waste Reduction Program (IWRP), and the DOE Defense Program Technology Transfer Initiative (TTI) provided partial funding for the LRSTF program.

\section{REFERENCES}

[1] R. L. Iman, D. J. Anderson, M. E. Armendariz, L. Lichtenberg, P. Van Buren, and M. T. Paffett, "Evaluation of a no-clean soldering process designed to eliminate the use of ozone depleting chemicals," SAND92-1776, Sandia National Laboratories, Albuquerque, NM, November, 1992.

[2] "Test plan for the evaluation of low-residue soldering in military applications," Low-Residue Soldering Task Force, Sandia National Laboratories, Albuquerque, NM, March 1994.

\section{DISCLAIMER}

This report was prepared as an account of work sponsored by an agency of the United States Government. Neither the United States Government nor any agency thereof, nor any of their employees, makes any warranty, express or implied, or assumes any legal liability or responsibility for the accuracy, completeness, or usefulness of any information, apparatus, product, or process disclosed, or represents that its use would not infringe privately owned rights. Reference herein to any specific commercial product, process, or service by trade name, trademark, manufacturer, or otherwise does not necessarily constitute or imply its endorsement, recommendation, or favoring by the United States Government or any agency thereof. The views and opinions of authors expressed herein do not necessarily state or reflect those of the United States Government or any agency thereof. 